Supplement of The Cryosphere, 12, 3033-3044, 2018

https://doi.org/10.5194/tc-12-3033-2018-supplement

(C) Author(s) 2018. This work is distributed under

the Creative Commons Attribution 4.0 License.

(c) (i)

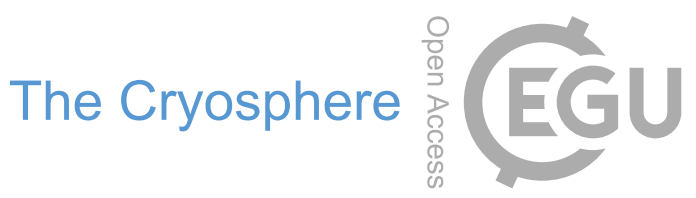

Supplement of

\title{
Modeling the effect of Ross Ice Shelf melting on the Southern Ocean in quasi-equilibrium
}

\author{
Xiying Liu \\ Correspondence to: Xiying Liu (liuxy@lasg.iap.ac.cn)
}

The copyright of individual parts of the supplement might differ from the CC BY 4.0 License. 


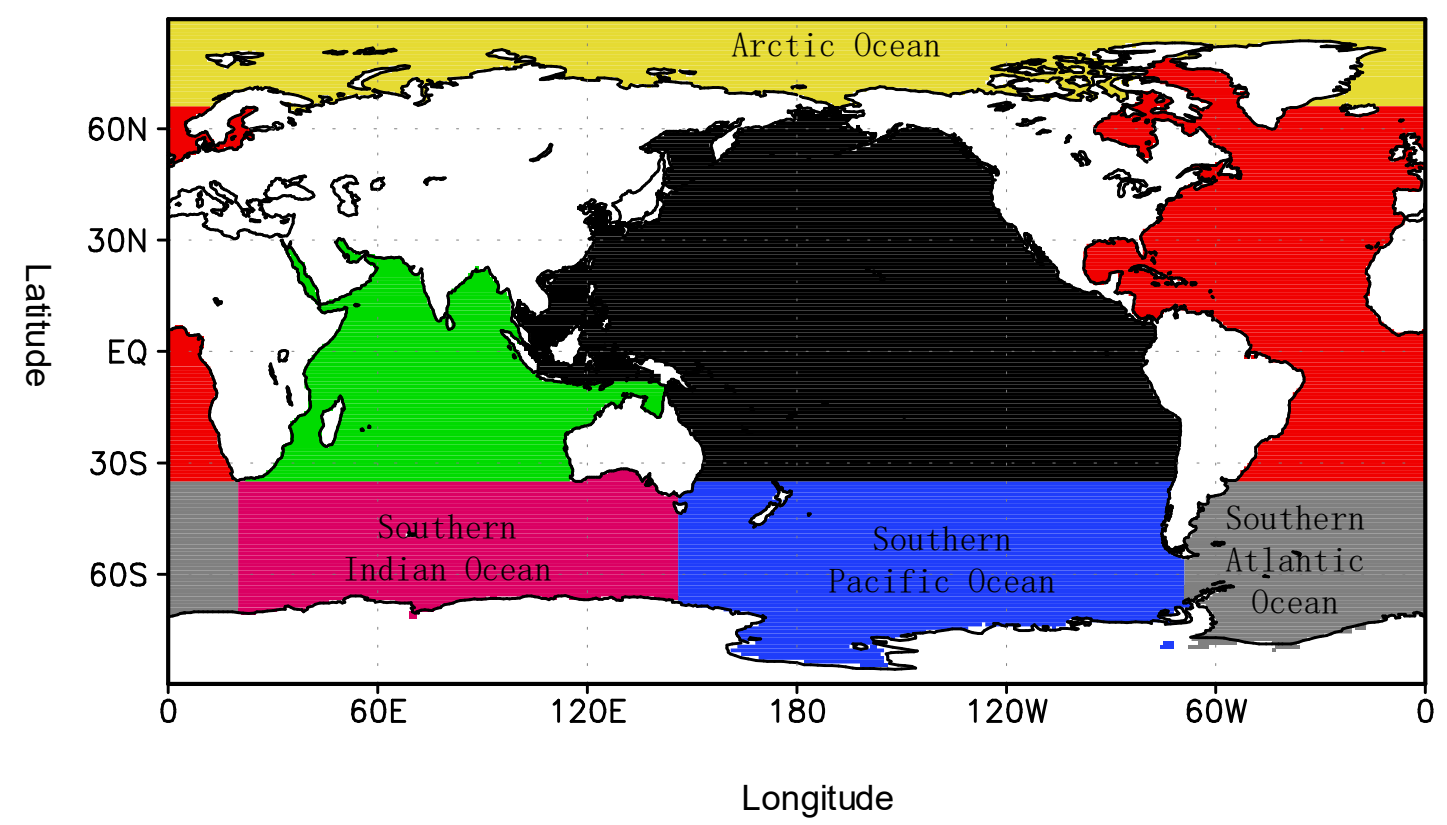

Fig. S1. Division of world ocean in $1 \times 1$ longitude-latitude grids

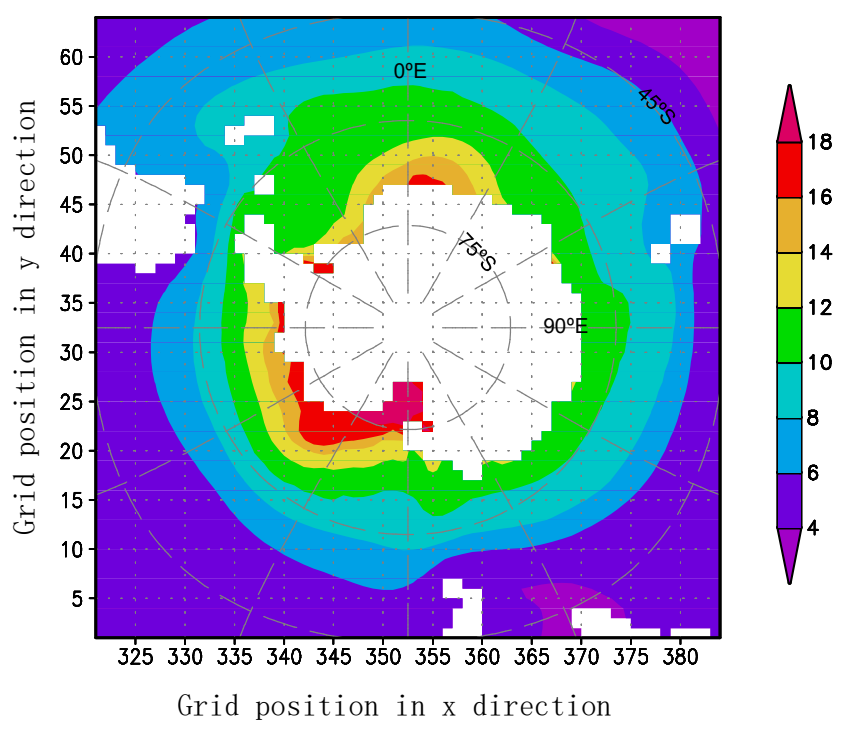

Fig. S2. Ratio of the coefficients of haline contraction and thermal expansion $\left(\beta \alpha^{-1}\right)$ at $390 \mathrm{~m}$ in EN. The units of $\beta$ and $\alpha$ are $\mathrm{kg} \mathrm{g}^{-1}$ and ${ }^{\circ} \mathrm{C}^{-1}$ respectively. 


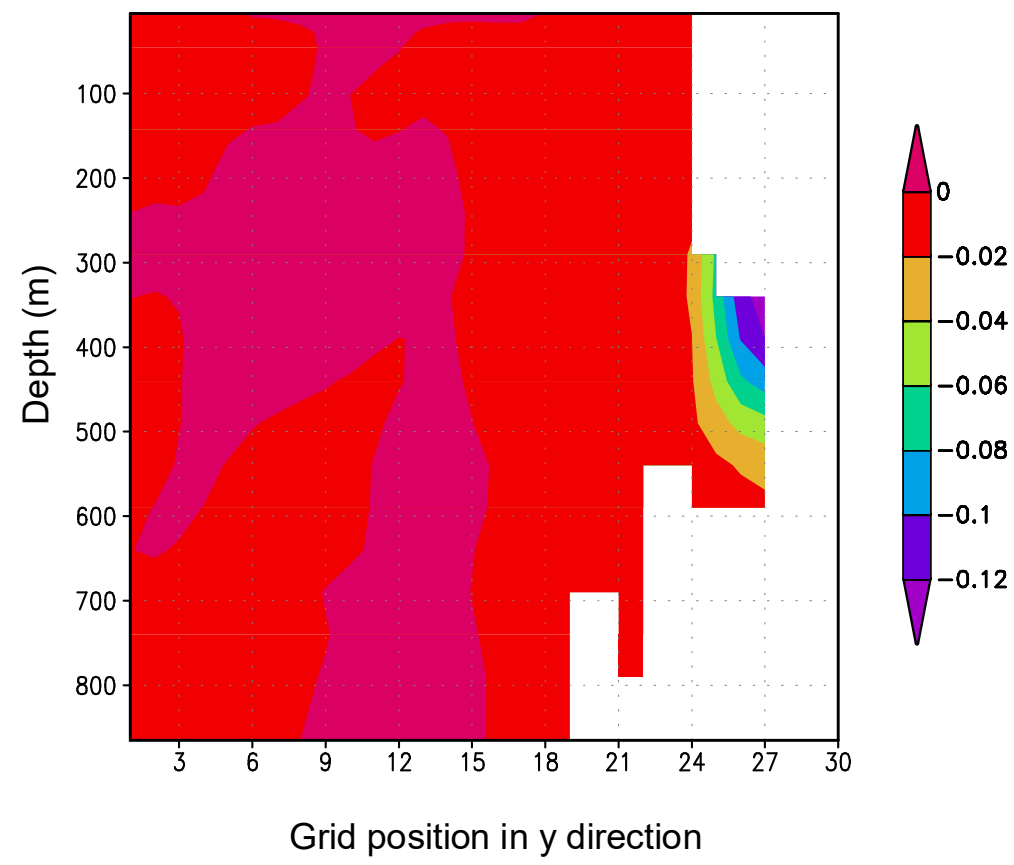

Fig. S3. Difference of density (EI minus EN) in the cross-section along $x=351$. The contour interval is $0.02 \mathrm{~kg} \mathrm{~m}^{-3}$.

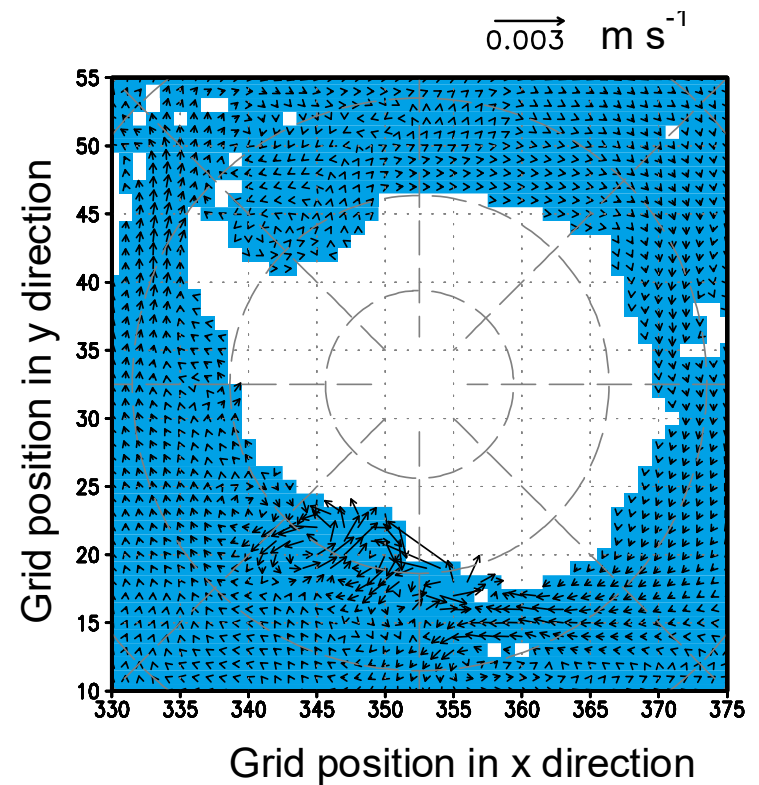

Fig. S4. Differences of annual mean ocean currents (EI minus EN) at $2065 \mathrm{~m}$. The unit of velocity is $\mathrm{m} \mathrm{s}^{-1}$. 